\title{
E-Communication and E-Learning Management Platforms: A Survey
}

\author{
V. Prashanthi, Research Scholar, Rayalaseeema University, Kurnool, Andhra Pradesh, India, \\ vangeepuramprashanthi@gmail.com \\ Y.Anuradha, Professor, Department of Business Management, ICFAI University, \\ ycannu@gmail.com
}

Abstract: E-Communication and learning requires the use of digital learning tools. Learning management systems and distance learning are among the most prevalent instruments during these days. But hybrid environments and partnerships are changing the landscape of learning strategies in online. Recent developments include the introduction of social networking and online learning communities, the omnipresent reach of smart phones and increased awareness of the potential for transforming learning for computer games. Other important developments include advances in Intelligent Tutoring Systems, the free movement of Open Educational Tools and the creation of immersive environments that allow users to interact with virtual environments and digitally increase their real-world experience.

Keywords - E-Communication Systems, E-Learning Systems, Intelligent Tutoring Systems, Learning Management System, Open Education Tools.

\section{INTRODUCTION}

E-learning can be described as promoting teaching and learning using electronic resources. One can experience elearning in many formats. These formats and delivery methods include stand-alone computers, the Internet, and learning materials satellites delivered by a teacher, an animated intelligent agent, or through media such as text, pictures, sounds, and video. E-learning can take place in virtually any location including schools, houses, and locations in remote fields. In addition, e-learning methods can be used at the learner's own speed. Many people with adequate resources and some knowledge of technology can use one way or another to engage in e-learning.

E-learning has been used throughout the United States and around the world at public and private primary, secondary, and post-secondary schools. In addition, home schoolers, government agencies, the military, and private businesses used e-learning as resources for learning and training. Since before the turn of the century, most colleges and universities around the world have made significant use of E-learning technologies (Wolfe, 2001). For-profit institutions like the University of Phoenix have become common features on the higher education landscape in recent years. The University of Phoenix, for example, offers 40 complete online bachelor's degrees ranging from a Bachelor of Arts in English to an RN Bachelor of Science in Nursing (Phoenix University, 2012). Learning management systems and distance education networks are the most prevalent methods for those applications.
Learning Management System Learning management systems are software applications that are used by educational systems as an electronic tool for giving students access to content on the course, and for monitoring, creating and incorporating relevant information on the course (Ellis, 2009). Students may access related course content, grades, email, and class discussion boards or forums using only a computer and Internet connection (Ellis, 2009). Online courses use learning management systems as their principal method of delivering information (Ellis, 2009). One drawback of these programs is that learning from the program cannot occur because the system itself does not instruct (Ellis, 2009). Learning management systems are essentially online tools which can be used as knowledge delivery method.

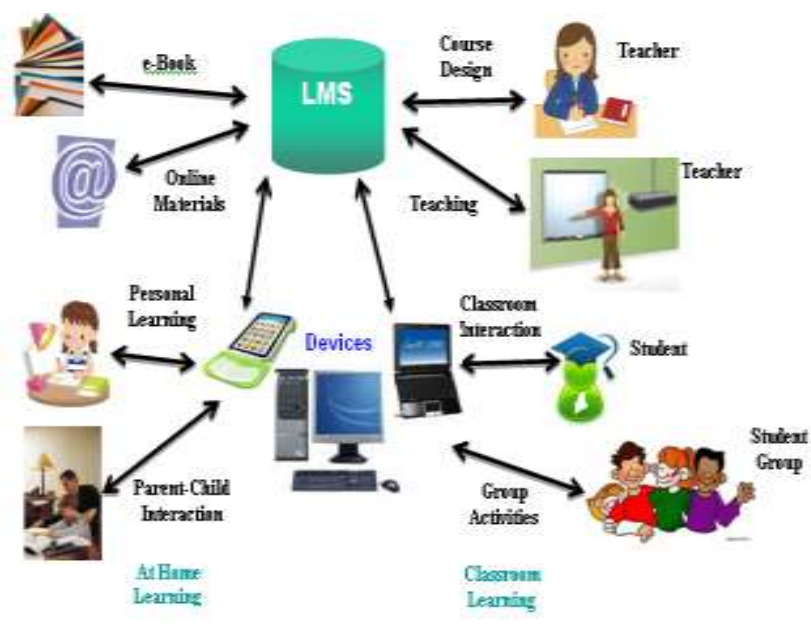

Figure 1. Architecture of a Common Learning Management System 


\section{RESEARCH METHODOLOGY}

Depending on the benefits of learning management systems in the field of education described in the previous section, the present study targets the existing conditions and solutions in these field including learning systems along with some challenges.

\section{A. Systematic Planning}

The analysis has involved with several conference and journal articles published in various reputed conference proceedings and journals. Firstly, a keyword-related search is performed from various list of indexed journals and several other management databases. The list of keywords used in the study are represented in Table 1 as

Table 1 Search Keywords

\begin{tabular}{|l|l|}
\hline \multicolumn{2}{|c|}{ Keywords } \\
\hline Online Education Portals & Open Sources for Education \\
\hline Web-based Learning Systems & Internet-based Learning \\
\hline Online Learning Systems & $\begin{array}{l}\text { Social-Media Learning } \\
\text { Communities }\end{array}$ \\
\hline
\end{tabular}

\section{B. Research Conduction}

This section deals with the summarization of selection criteria to evaluate the existing learning management systems. The entire system is survey by continuation the existing systems to the below research questions:

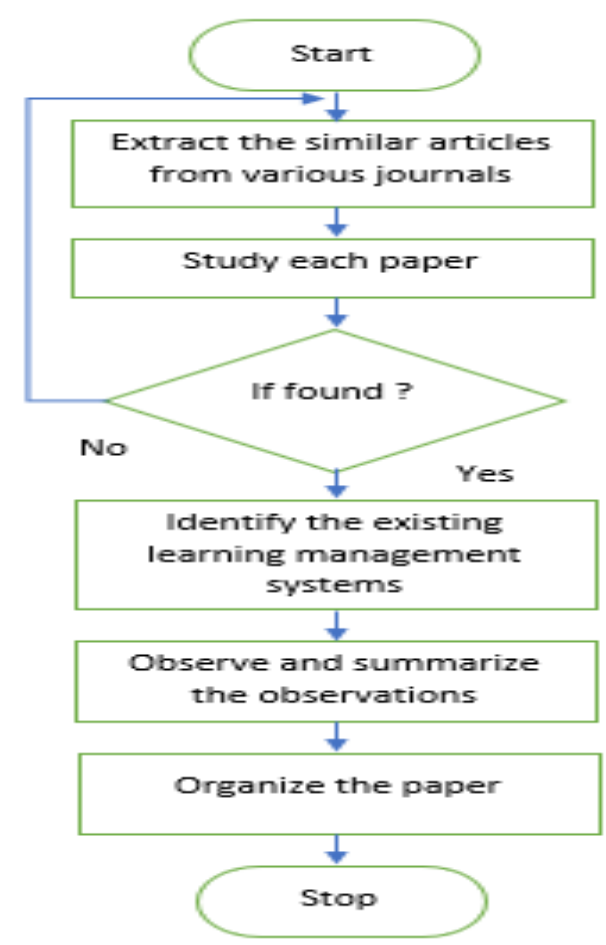

Figure. 2 Research Methodology for Learning Management Systems

1. What are the open resources available to obtain online management systems?

2. What are the automated systems that can adopt the web-based learning techniques?
3. What are the open online tools available to provide education and other interactive services?

4. What is the impact of social media websites contributing to the learning management?

5. How mobile-based learning systems contributing to e-learning?

\section{OPEN RESOURCES FOR EDUCATION}

Open Educational Tools are free online media, as well as documents used to teach and learn. These resources are distributed through platforms that allow educational materials to be produced and delivered including college courses and materials [1]. This way, students taking courses do not pay tuition or receive credit, nor are they given degrees.

Universities and grants fund these services. One source of support for open educational resources is the Open Educational Services campaign, whose aim is to promote cooperation, awareness, and education worldwide [1]. Open Education in recent years has attracted the attention of journalists, partially because some of the world's most respected universities have become involved in the massive online open-course movement. The MIT project, called MIT Open Courseware, was the first program to provide open educational resources in 2001, sparking the campaign for Open Educational Tools [1].

In 2002 MIT Open Courseware began offering its entire course catalog online at no discount. MIT currently has more than 2080 courses available online; the available content ranges from reading lists, discussion topics, homework problems and tests, lecture notes, and lecture video streaming. Open courseware's foreign members include: Brazil, Mexico, China, India, Japan, Germany and the Netherlands [1]. The Stanford Engineering Everywhere (SEE) project, launched by Stanford University, is a program that offers many free online courses taught by Stanford professors.

Such classes include instructional videos, lists of readings, assignments, classroom lectures, and are available globally [9]. As of 2012, Stanford's School of Engineering offers 10 courses [9]. The SEE allows students to use material from the course for any reason that suits their needs. In addition, the SEE allows educators to use their presentations, handouts, notes, or assessments in their own classrooms to promote cooperation [9]. 


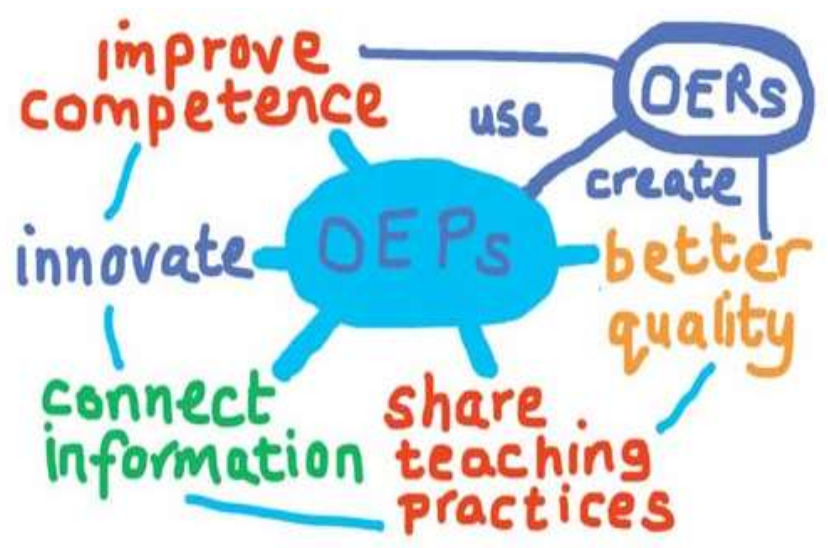

Figure 3. Functionality of Open Educational Resources

There are currently more than 200 institutions worldwide which are part of the Open Courseware Consortium. These include Europe's Learning Technology Exchange for Colleges, Washington State's Open Course Library Project, California Learning Resources Network, China Digital Tools for Education, Open Courseware in Japan, and various projects for countries such as Bangladesh, Uruguay, South Korea, South Africa and Saudi Arabia to digitize textbooks at all levels [1].

Accessible educational resources are also available for grades $\mathrm{K}-12$. Curriki is a non-profit organization providing primary school students with an open source curriculum website that offers universal access to related curriculum and other educational materials [6]. The Curriki community provides educational materials to its members, such as multimedia textbooks, learning videos, and other interactive services that are peer-reviewed as meeting conventional educational standards [6]. The active leadership and peer review of highly respected institutions has kept in check that expectations that e-learning is becoming a second-rate alternative to more costly conventional colleges and universities.

\section{WEB-BASED ONLINE LEARNING COMMUNITIES}

Online learning communities are peer-to-peer learning communities whose members communicate via the Internet. A subject area will be identified and discussed among participants in these virtual communities to gain knowledge of the topic. Data can be transmitted through any medium provided by the Internet, including audio, video, text, images, internet connections, and virtual files. Members of the Community can upload and download files as needed.

\section{A. Social Media}

Social networking sites like Facebook, Twitter, and Googley allow users to connect with anyone around the globe via the Internet. Facebook, the largest social networking site in the world, has over 1 billion registered users [10], and educators are turning to these sites to communicate with their students. Teachers can' share' relevant material onto a social networking site and students can access the details and explore the content further [2]. This platform allows students to get a new and versatile learning experience. Using social networking in education can be advantageous because students are exposed to these networks constantly, making them easier, quicker, and more convenient to access class material. In fact, it allows students who would otherwise not participate in the classroom to engage in material from the safety of their computers. Social networks focused on education, such as Live Mocha, offer instruction in foreign languages in a peer-to-peer learning environment that works together. Live Mocha has over 15 million users, and feedback is' crowdsourced' because people who want feedback have to provide input to other online community members.

\section{B. Mobile Learning Platforms}

Mobile computing has been proposed to be the future of Elearning. The emergence of e-books, tablets and the omnipresence of smart phones make mobile computing devices the medium of choice-particularly for' digital natives,' i.e. generations who have never known a world without the Internet and a range of computing technologies [4]. Mobile computing is the use of a device that is easily transported, such as a laptop that the user communicates with constantly all day. This involves the use of mobile computing, software, and hardware. Mobile computers can do just about anything from a desktop computer that one can do. Web and email access capabilities include editing and viewing documents and images, playing games, and accessing apps and other programs. Mobile computing has its disadvantages which can make it somewhat more difficult to use compared to a personal computer. Limitations include slower and less stable access to the Internet, lower security, power consumption that exceeds battery capacity and smaller workspace. Mobile phones and tablets are among the most popular methods of mobile computing. Certain tools for mobile computing include portable computers, personal digital assistants (PDA) and calculators for graphing.

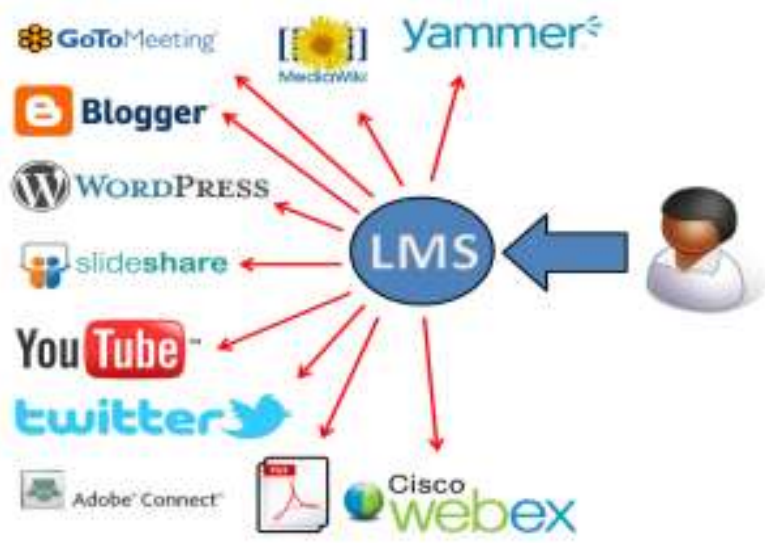

Figure 4. Web-Based Learning Management System 
Recently educators in their primary school classrooms have been encouraged to use smart phones to engage students in learning. The advantages of using these technologies include improved student participation, increased accessibility and greater interest in education. Project KNect is one program that gives students access to smartphones and mobile applications that can clarify algebraic concepts and allows them to seek advice from their peers via text or instant messages; the software showed increases in the academic success of students by 30 percent compared to their peers who did not use the program [7]. Furthermore, informal learning environments like Live Mocha are gradually making versions of their entire tool suite tailored for mobile platforms.

\section{E-Campus}

The E-Campus initiative was a collaboration between Microsoft and the Massachusetts Institute of Technology (MIT), which was launched with the goal of improving technology-enabled teaching models and developing new educational instruments. The E-Campus project aimed to develop methods to allow users to access laboratory instruments remotely, create tools for the sharing of educational materials, provide access to distance learning and mentoring, and create virtual museums based on the Internet. Although the initial E-Campus initiative ended in 2006, there is now a project called Outreach Initiative which aims to disseminate the educational technologies developed from the E-Campus initiative. The iLabs project allows users to access remote laboratories online and conduct experiments they might otherwise be unable to perform, despite their limited resources. The Cross-Media Annotation Program (xMAS) enhances the use of video and images in courses that often discuss visual materials. XTutor is a software with audio recordings and lecture transcripts, homework problems and an online smart tutoring system for introductory computer science and Artificial Intelligence courses. The initiative is iMOAT, a web-based service that allows the write assignments and tests to be evaluated. Technology-enabled Active Learning (TEAL) provides an immersive learning experience by incorporating seminars, simulations, collaboration, and interactive access to student-desk experiments. Finally, the Peer Review Evaluation Process (PREP) is designed to be used by teams of four to six people so that they can create and share ideas with each other; for example, students of mechanical engineering used PREP to design and build competition robots. Tools like these have the capacity for smudge, the boundary between teaching and research at large and small institutions worldwide.

\section{Conclusion}

E-communication and e-learning topography is rapidly changing, and the rate of change is dramatically increasing.
Mobile networked digital devices are becoming quicker, more efficient, and more omnipresent at the technology level, enabling e-learning to occur most where. Big data' can provide new tools in many ways to adapt the learning experiences to individual and cultural differences. With voice, touchscreen, and gestures increasingly feasible as forms of interactive learning, new discourse innovations are opening alternatives to the keyboard. Computer development remains faster than software progress, and success in both meets the theory of social and psychology. Such changes shake educational institutions at all levels, yet the hyperbolae about the extinction of brick and mortar schools and universities are largely unjustified. Counter evidence involves amazingly high dropout rates in massive open online courses, as well as the fact that a viable business model does not sustain them.

Although there are real socio-cultural changes reflected in digital natives, real learning is still very hard work, which does not lend itself to rapid technical adjustments.

\section{REFERENCES}

[1]. Caswell, T., Henson, S., Jensen, M., Wiley, D., 2008. Open educational resources: enabling universal education. International Review of Research in Open and Distance Learning, 2008.

[2]. Davis, M.R., 2010. Social networking goes to school. Education Week Digital Directions, 2010, pp. 16-23.

[3]. Ellis, R.A., 2009. Students' Experiences of E-Learning in Higher Education: The Ecology of Sustainable Innovation. Routledge, New York, 2009.

[4]. Halpern, D.F., Keith Millis, K., Graesser, A.C., Butlerd, H., Forsyth, C., Caic, Z., 2012.

[5]. Operation ARA: a computerized learning game that teaches critical thinking and scientific reasoning. Thinking Skills and Creativity 7, 93-100.

[6]. Kurshan, B., OER models that build a culture of collaboration: a case exemplified by Currik. eLearning Papers 10, 2008, 1-8.

[7]. Pierce, D., Summit: Mobile Computing is Education's Future, 2010.

[8]. University of Phoenix, Degree Programs, 2012.

[9]. Van Orsdel, L., Openness: Contribute, Access, 2012.

[10]. Vance, A., Facebook: The Making of 1 Billion Users. Bloomberg Businessweek, 2012.

[11]. Wolfe, C.R., Learning and Teaching on the World Wide Web. Academic Press, San Diego, CA,2001. 